\title{
Long-term change in respiratory function following spinal cord injury
}

\author{
L van Silfhout ${ }^{1,2}$, AEJ Peters ${ }^{1,2}$, DJ Berlowitz ${ }^{2}, \mathrm{R}$ Schembri $^{2}$, D Thijssen ${ }^{1}$ and M Graco ${ }^{2}$
}

\begin{abstract}
Study design: Retrospective study.
Objectives: To model the effect of time since injury on longitudinal respiratory function measures in spinal cord injured-individuals and to investigate the effect of patient characteristics.

Setting: A total of 173 people who sustained a spinal cord injury between 1966 and April 2013 and who had previously participated in research or who underwent clinically indicated outpatient respiratory function tests at the Austin Hospital in Melbourne, Australia, were included in the study. At least two measurements over time were available for analysis in 59 patients.

Methods: Longitudinal data analysis was performed using generalised linear regression models to determine changes in respiratory function following spinal cord injury from immediately post injury to many years later. Secondly, we explored whether injury severity, age, gender and body mass index $(\mathrm{BMI})$ at injury altered the time-dependent change in respiratory function.

Results: The generalised linear regression model showed no significant change $(P=0.276)$ in respiratory function measured in (forced) vital capacity ( $(F) V C)$ after the spinal cord injury. However, significant $(P<0.05)$ differences in respiratory function over time were found when categorising age and BMI.

Conclusion: This clinical cohort with long-term, repeated measurements of respiratory function showed no significant overall change in respiratory function over 23 years. However, a decline in respiratory function over time was observed in subgroups of individuals older than 30 years at the onset of injury and in those with a BMI $>30 \mathrm{~kg} \mathrm{~m}^{-2}$.
\end{abstract}

Spinal Cord (2016) 54, 714-719; doi:10.1038/sc.2015.233; published online 12 January 2016

\section{INTRODUCTION}

Lesion-dependent loss of respiratory muscle innervation caused by spinal cord injury (SCI) leads to the immediate impairment of respiratory muscle functioning and an associated reduction in lung volume. ${ }^{1}$ Respiratory impairment after SCI causes respiratory complications $^{2}$ such as pneumonia, atelectasis, pleural effusions, sleep-disordered breathing or symptoms such as dyspnoea, in $50-67 \%$ of the patients. ${ }^{3}$ Garshick et al. ${ }^{4}$ showed that during the first year post injury the respiratory system was the cause of death in $28 \%$ of the cases and in $22 \%$ of the cases thereafter. Pneumonia has been shown to be the most common cause of death in patients with a SCI. ${ }^{5}$ These respiratory complications during the first 2 years post injury have substantially decreased over the last 30 years, whereas respiratory complication rates in chronic SCI have not altered. ${ }^{6}$

Multiple factors may influence the high rate of respiratory complications in this population. Some of these include poor a priori respiratory function, ${ }^{7,8}$ changes in breathing mechanics, ${ }^{9}$ and reduction of the elastic properties of the thorax with increasing time post injury. ${ }^{10,11}$ Lesion level also seems to be involved, as it has been shown that lung function decreases ${ }^{7}$ and respiratory tract infections increase ${ }^{8}$ with higher lesion level. However, patients with a SCI are able to train their remaining muscles, which can result in substantial variability in respiratory function measures across time in patients with the same lesion level. ${ }^{12}$
Sinderby et al. ${ }^{13}$ showed no significant change in vital capacity from early (1-3 years) to later (10 or more years) time post injury in patients with tetraplegia. Other studies even showed large improvements in lung function during the first 6 months post injury, which became smaller thereafter. ${ }^{14-17}$ Resolution of the impact of spinal shock, usually during the first 4-6 months post injury, and thus lung function, could explain these findings. ${ }^{18}$ Nonetheless, there are little data describing the effect of time since injury on respiratory function in SCI. ${ }^{19}$ Therefore, the first aim of the study was to describe the change in respiratory function following the early changes after a spinal injury in a clinical cohort.

In subjects with a SCI, similar to the able-bodied population, respiratory function is influenced by parameters such as gender, body mass index (BMI), age and severity of the injury. ${ }^{13,20-22}$ However, whether these parameters influence the changes in (F)VC following a SCI have not yet been investigated. The bulk of the literature is based on cross-sectional comparison. Currently, little is known about factors influencing the change in pulmonary function across time in SCI individuals. A better understanding of these factors may improve therapeutic interventions and approaches (for example, patient selection or identification) to prevent respiratory complications and potentially decrease respiratory morbidity and mortality. Therefore, the second aim of this paper was to investigate the effect of age at

${ }^{1}$ Radboud University Nijmegen Medical Centre. Department of Physiology, Nijmegen, The Netherlands and ${ }^{2}$ Institute for Breathing and Sleep. Austin Health, Heidelberg, Melbourne, VIC, Australia

Correspondence: L van Silfhout, Radboud University Nijmegen Medical Centre. Department of Physiology, 6500 HB, Nijmegen, The Netherlands.

E-mail: lysannevansilfhout@live.nl

Received 14 May 2015; revised 30 November 2015; accepted 1 December 2015; published online 12 January 2016 
injury, gender, BMI and severity of injury on the change in (F)VC after a SCI.

\section{SUBJECTS AND METHODS}

\section{Study design and patient population}

Clinical and research databases at the Austin Hospital in Melbourne, Australia, were used to identify patients with SCI who had participated in previous research or had outpatient respiratory function tests (RFTs) completed. Only patients who had a SCI and one or more RFTs with a known time since injury were included in this study. This data audit was approved by the Austin Health Human Ethics Committee.

\section{Lung function measurements}

Lung function measurements were made in an accredited respiratory function laboratory at the Austin Hospital. Spirometers were calibrated daily and RFTs made in accordance with the relevant $\mathrm{ATS}^{21}$ and ERS/ATS ${ }^{23}$ recommendations at the time of data collection. Briefly, patients were instructed to exhale fully from total lung capacity, through a mouthpiece while wearing a nose clip, until three reproducible and acceptable measurements were registered. The highest measured value was quoted for further analysis. Analyses were performed on the forced vital capacity (FVC) if available. If the FVC was not reported, then the VC was substituted. Change over time was modelled from patients with at least two technically acceptable measures over time.

\section{Statistical analysis}

Descriptive statistics (mean, s.d., median and range) for group characteristics of all the included patients and the subset of patients who were included in the analysis were calculated separately. Severity of injury was categorised according to the DeVivo et al. ${ }^{24}$ recommendations. Comparisons between the total sample and the subset with at least two repeated FVC values within 23 years since injury were made to examine any differences using $t$-tests and $\chi^{2}$ as appropriate.
The longitudinal data were initially visualised in Microsoft Excel (The Austin Hospital, Melbourne, VIC, Australia) to explore how the available data were spread over time since injury at the date of the RFT. Stata12 (The Austin Hospital) was used to create a generalised linear regression model to describe the change in (F)VC over time. In this model, the (F)VC is the outcome variable, the time since injury is the predictor and the patient is the random variable, to account for all patient characteristics and individual variables.

Subsequently, regression interaction analyses were performed in Stata12 to investigate the influence of age and BMI at the time of injury, gender and injury severity on the change in (F)VC over time. Age at injury was split into three groups for the ages 18-30 years, 31-60 years and older than 60 years, following the recommendations of DeVivo et al..$^{24} \mathrm{BMI}$ at the time of injury was also split into three groups according to standard BMI classification; ${ }^{25} \mathrm{BMI}<25$, BMI $25-30$ and BMI $>30$. Severity of injury was categorised according to the DeVivo et al..$^{24}$ recommendations; however, in the subgroup of patients selected for analysis, there were no patients with an AIS E injury. For each of the categories, the individual slopes of the change over time were calculated and then compared to determine whether the variable has a significant influence on the change over time in (F)VC.

\section{RESULTS}

In this study, 180 patients with one or more RFT measurements were identified. The time since injury was known for 173 patients who sustained a SCI between 1966 and April 2013. The corresponding RFTs were conducted between 1996 and September 2014. Of the 311 RFTs conducted, FVC was not available for 19, and therefore VC was substituted. The characteristics of the 173 patients are described in Table 1.

For analysis of the longitudinal data, we included the 59 patients (34\%) who underwent two or more RFTs. Figure 1 illustrates the selection process of patients in this study.

Table 1 Patients' characteristics of the whole sample $(n=173)$ and the subset for analysis $(n=59)$

\begin{tabular}{|c|c|c|c|}
\hline & Total group & Group with two or more RFTs with cut point of 23 years post injury & P-value \\
\hline $\mathrm{N}$ & $173^{\mathrm{a}}$ & 59 & \\
\hline Gender & & & 0.31 \\
\hline Male & $131(76 \%)$ & $42(71 \%)$ & \\
\hline Female & $42(24 \%)$ & 17 (29\%) & \\
\hline Mean age at injury in years (s.d., median, range) & $36(16,33,1-84)$ & $40(16,37,18-71)$ & 0.04 \\
\hline Mean BMI in $\mathrm{kg} \mathrm{m}^{-2}$ (s.d., median, range) & $26.3(5.7,25.4,15.9-52.9)$ & $28.2(6.8,26.8,16.0-52.9)$ & $<0.001$ \\
\hline Smoking history & & & 0.09 \\
\hline Never smoked & $64(37 \%)$ & $20(34 \%)$ & \\
\hline Stopped smoking & $70(40 \%)$ & $30(51 \%)$ & \\
\hline Currently smoking & $39(23 \%)$ & $9(15 \%)$ & \\
\hline Severity of injury & & & 0.27 \\
\hline $\mathrm{C} 1-\mathrm{C} 4, \mathrm{AIS} \mathrm{A}, \mathrm{B}, \mathrm{C}$ & $30(17 \%)$ & $10(17 \%)$ & \\
\hline C5-C8, AIS A, B, C & $69(40 \%)$ & $30(51 \%)$ & \\
\hline T1-S5, AIS A, B, C & $29(16 \%)$ & $9(15 \%)$ & \\
\hline AIS D & $38(22 \%)$ & 9 (15\%) & \\
\hline AIS E & 3 (2\%) & $0(0 \%)$ & \\
\hline Unknown & $4(3 \%)$ & $1(2 \%)$ & \\
\hline
\end{tabular}

Abbreviations: AIS, American Spinal Injury Association Impairment Scale; BMI, body mass index; RFT, respiratory function test

Data are $n(\%)$ unless otherwise stated.

aPatients with known time since injury at each RFT; the number used to calculate proportions for other characteristics. 
The frequency of RFT measures was anticipated to decrease over time after injury, and the 'density' or 'frequency' of the measures of (F)VC would affect the validity of the regression modelling. There is no agreed statistical technique to determine the optimum frequency of data samples in time series analysis such as that proposed for these data. As such, Figure 2 was constructed to facilitate visual inspection of data density and to select a cutoff point for analysis of the effect of time after injury. As illustrated below, there is a clear reduction in the frequency of data collection after 23 years, and therefore this time was chosen as the censoring time post injury.

\section{Change in pulmonary function in SCI}

Characteristics of the sample of those with two or more RFTs performed up to 23 years post injury $(n=59)$ are described in

\begin{tabular}{|c|c|}
\hline $\begin{array}{l}180 \text { patients with one or } \\
\text { more RFT measure } \\
\text { (RFTs } n=337 \text { ) }\end{array}$ & \multirow{2}{*}{$\begin{array}{l}7 \text { patients with an } \\
\text { unknown date of injury } \\
\text { (RFTs } n=26)\end{array}$} \\
\hline$\downarrow$ & \\
\hline $\begin{array}{l}173 \text { patients with one or } \\
\text { more RFT measure and a } \\
\text { known date of injury } \\
\text { (RFTs } n=311 \text { ) }\end{array}$ & \multirow{2}{*}{$\begin{array}{l}105 \text { patients with just one } \\
\text { RFT measure } \\
\text { (RFTs } n=105 \text { ) }\end{array}$} \\
\hline & \\
\hline \multirow{2}{*}{$\begin{array}{l}68 \text { patients with two or } \\
\text { more RFT measures and a } \\
\text { known date of injury } \\
\text { (RFTs } n=206 \text { ) }\end{array}$} & (RFTs n=105) \\
\hline & 9 patients with one or \\
\hline 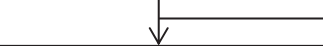 & more RFT measure beyond \\
\hline $\begin{array}{l}59 \text { patients with two or } \\
\text { more RFT measures and a } \\
\text { maximal time since injury } \\
\text { of } 23 \text { years post } \\
\text { (RFTs } n=177 \text { ) }\end{array}$ & (RFTs $n=29$ ) \\
\hline
\end{tabular}

Figure 1 Selection of patients.
Table 1 and compared with the total sample $(n=173)$. Comparison of this subgroup with the total group shows that patients in the subgroup were on average 4 years older $(P=0.04)$ and slightly more overweight $(P<0.001)$.

Results from the linear model analysis showed a slope of -0.01 (s.e.m. $0.01,95 \%$ CI: $[-0.03,0.01] ; P=0.28$ ), indicating that there was no significant change in $(\mathrm{F}) \mathrm{VC}$ over time.

To assess the validity of substituting VC when FVC was unavailable, we performed a sensitivity analysis on the original data set, whereby we repeated the analysis using only those with two or more FVC measurement $(n=54)$ and only those with two or more VC measurements $(n=42)$. As with the primary analysis, these models showed no change in the respiratory function using either measure, with a FVC slope of 0.01 (s.e.m. 0.01, 95\% CI: [-0.03, 0.01]; $P=0.48$ ) and a VC slope of 0.00 (s.e.m. $0.01,95 \%$ CI: $[-0.02$, $0.02] ; P=0.99)$.

Factors related to the change in pulmonary function in SCI The characteristics of the different age, gender, BMI and injury severity categories of the subgroup of 59 patients are described in Table 2. Injury severity was unknown for one patient, who was therefore excluded from this analysis $(n=58)$. The individual slopes for every category regarding change in $(\mathrm{F}) \mathrm{VC}$ for every variable are plotted in Figure 3.

A significant difference was found when comparing the slopes between $18-30$-year olds and 31-60-year olds $(P=0.003)$. There were no differences between 18-30-year olds and those older than 60 $(P=0.222)$ nor $31-60$-year old and those older than $60(P=0.799)$.

There was no difference in change in $(\mathrm{F}) \mathrm{VC}$ over time between males and females $(P=0.16)$.

When comparing BMI categories, a significant difference in change over time was found between people with a BMI $<25 \mathrm{~kg} \mathrm{~m}^{-2}$ and $>30 \mathrm{~kg} \mathrm{~m}^{-2}(P<0.001)$ and people with a BMI of $25-30 \mathrm{~kg} \mathrm{~m}^{-2}$ and $>30 \mathrm{~kg} \mathrm{~m}^{-2}(P=0.024)$. People with a BMI $>30 \mathrm{~kg} \mathrm{~m}^{-2}$ showed a decline in (F)VC over time. No significant difference was found when comparing people with a $\mathrm{BMI}<25 \mathrm{~kg} \mathrm{~m}^{-2}$ and $25-30 \mathrm{~kg} \mathrm{~m}^{-2}$ $(P=0.511)$.

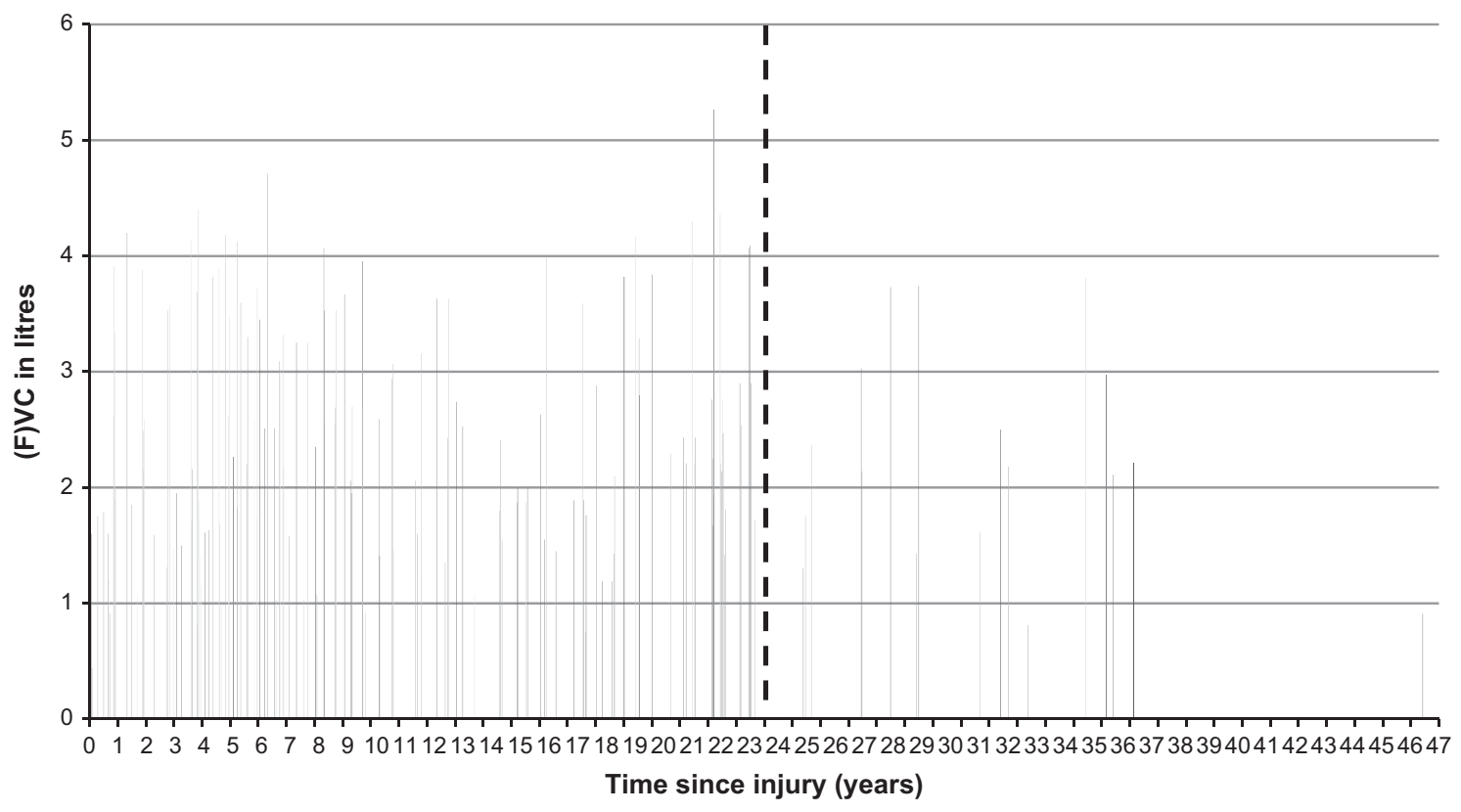

Figure 2 Individual (F)VC records plotted against time since injury. 
Table 2 Results from regression interaction analysis regarding age, gender, BMI and injury severity

\begin{tabular}{|c|c|c|c|c|c|c|}
\hline Variable & Category & Patients (n) & RFTs (n) & Individual slopes & $95 \% \mathrm{Cl}$ & P-value \\
\hline \multirow[t]{3}{*}{ Age (years) } & $18-30$ & 21 & 53 & 0.027 & $-0.004,0.059$ & 0.092 \\
\hline & $31-60$ & 29 & 88 & -0.029 & $-0.049,-0.010$ & 0.003 \\
\hline & $>60$ & 9 & 36 & -0.020 & $-0.089,0.049$ & 0.570 \\
\hline \multirow[t]{2}{*}{ Gender } & Male & 42 & 125 & -0.014 & $-0.034,0.006$ & 0.156 \\
\hline & Female & 17 & 52 & 0.001 & $-0.025,0.027$ & 0.934 \\
\hline \multirow[t]{3}{*}{ BMI $\left(\mathrm{kg} \mathrm{m}^{-2}\right)$} & $<25$ & 19 & 57 & 0.020 & $-0.005,0.044$ & 0.115 \\
\hline & $25-30$ & 21 & 57 & 0.005 & $-0.034,-0.043$ & 0.821 \\
\hline & $>30$ & 19 & 63 & -0.047 & $-0.071,-0.024$ & $<0.001$ \\
\hline \multirow[t]{4}{*}{ Injury severity ${ }^{b}$} & $\mathrm{C} 1-\mathrm{C} 4, \mathrm{AIS} A, \mathrm{~B}, \mathrm{C}$ & 10 & 28 & -0.008 & $-0.043,0.027$ & 0.656 \\
\hline & $\mathrm{C} 5-\mathrm{C} 8, \mathrm{AIS} A, \mathrm{~B}, \mathrm{C}$ & 30 & 81 & -0.002 & $-0.029,0.024$ & 0.857 \\
\hline & T1 - S5, AIS A,B,C & 9 & 34 & 0.001 & $-0.029,0.031$ & 0.929 \\
\hline & AIS D & 9 & 30 & -0.019 & $-0.071,0.032$ & 0.459 \\
\hline
\end{tabular}

Abbreviations: AIS, American Spinal Injury Association Impairment Scale; BMI, body mass index; RFT, respiratory function test.

aThe listed $P$-value and $\mathrm{Cls}$ in the table test whether the gradient of the regression is statistically different to zero, that is, a straight (horizontal) line.

${ }^{\text {b}}$ The analysis regarding injury severity is based on 58 patients, since the 1 patient with unknown injury severity was excluded from this analysis.
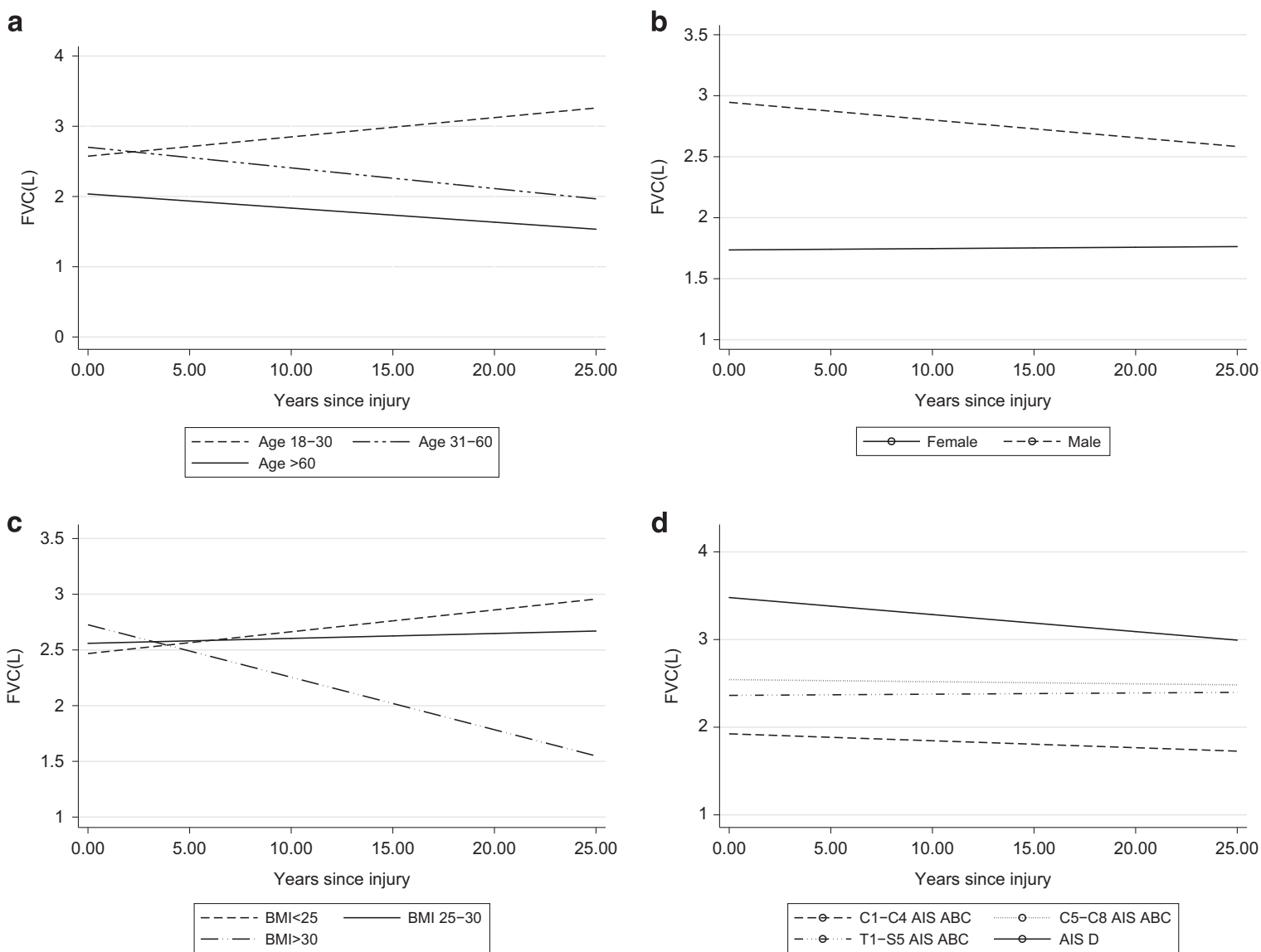

Figure 3 Interaction plots of (F)VC over time (a) by age category, (b) by gender, (c) by BMI category and (d) by injury severity category.

When comparing the different categories of injury severity, no differences were found in change in (F)VC over time. Those with AIS $\mathrm{D}$ had a higher baseline pulmonary function than those AIS A,B,C with high cervical injuries.

\section{DISCUSSION}

This paper provides novel information regarding the change in respiratory function, specifically the (F)VC over time after SCI. We were able to model change over time in participants up to 23 years after injury and have demonstrated that, after the initial drop in pulmonary function, little further changes are observed. However, specific groups of participants demonstrated particular patterns. Those participants with a BMI in the obese range at baseline and middle-aged subjects at the age of SCI onset showed a substantial decline in pulmonary function over time. This study provides novel and important insight into factors that alter the change in pulmonary function across time in a group of SCI individuals. 
There have been few studies addressing issues regarding ageing and SCI in respiratory function. ${ }^{26}$ Available data on this topic suggest that inspiratory capacity, and therefore $\mathrm{FVC},{ }^{27}$ reduces after a SCI because of higher abdominal compliance. Consequently, this impacts functional residual capacity as the diaphragm is less elevated due to the lack of tone in the abdominal muscles. This is pronounced in individuals with tetraplegia and high-level paraplegia. $^{28}$ Mueller et al. ${ }^{29}$ showed a decline in respiratory function with ageing in individuals with a SCI of -0.012 to -0.021 litres per year, which is less than that reported in able-bodied people $(-0.026$ to -0.043 litres per year). ${ }^{30}$ Postma et al. ${ }^{31}$ showed that many patients with SCI have a larger decline in respiratory function in the first 5 years post injury, than can be explained by age-related decline. The results from both studies are in contrast with the finding of this study that respiratory function after SCI does not significantly decline. However, Mueller et al..$^{29}$ and Postma et al. ${ }^{31}$ only investigated a short follow-up of 1 year post discharge and 5 years post injury, respectively, which differs substantially from the current study follow-up time frame of up to 23 years post injury. Tow et al., ${ }^{32}$ however, had a follow-up time of 20 years in their study, which did show a significant decline in vital capacity over the years. However, those authors only included tetraplegic patients, whereas in this study both tetra- and paraplegic patients were included.

In the second part of this study, we aimed to identify factors that may alter the change across time. Interestingly, we found significant changes over time between patients younger than 30 years of age and patients older than 30 years and between patients with a BMI of $<30$ and those with a BMI $>30$. The fact that there was no statistically significant difference between age 18-30 and $>60$ was probably because of the small sample $(n=9)$ of the oldest age group in this study and an associated poor statistical power. As such, it may be concluded that age $>30$ and a BMI $>30$ have a greater effect on the (F) VC decline over time.

The negative influence of a BMI $>30$ at baseline on the (F)VC over time is supported by the findings of Jones et al., ${ }^{33}$ who have shown that a BMI $>30$ negatively influences the vital capacity in able-bodied participants. Chen et al. ${ }^{34}$ also showed that in an able-bodied population the respiratory function is decreased when overweight. This suggests that obesity importantly affects changes in respiratory function across time, an effect that is not altered by the presence of a SCI. Stolzmann et al. ${ }^{35}$ have also demonstrated that longitudinal change in FVC is attributable to factors such as age and BMI. However, that study was only performed in male patients with SCI. In our study, both male and female patients with SCI were included; therefore, our results are applicable to all patients with SCI regardless of gender. Furthermore, no effect of gender was observed.

\section{Clinical relevance}

This study has shown the effect of time since injury on respiratory function in patients with SCI. As there is currently very limited published data available on the impact of time since injury, a better understanding of the physiology of respiratory function after SCI may provide insights for improved therapeutic interventions and respiratory care. These study results suggest that a serial decline in the respiratory function in a person with SCI may reflect a sign of disease, instead of normal ageing as typically observed in the able-bodied population. This study focused on the (F)VC because of its broad prognostic utility and relationship with possibly important outcomes like the need for intubation and tracheostomy.
Further, this study has shown that patients older than 30 at the time of their injury, and those with a BMI greater than 30 , are likely to show a decline in respiratory function. In groups other than these, our data would suggest that any demonstrable decline in (F)VC may warrant clinical review. ${ }^{36}$

\section{Study limitations}

It was not possible to determine which RFTs were performed for diagnostic or research purposes, and therefore it is impossible to exclude the possibility that some of the RFTs were completed when the patient was experiencing a respiratory complication (and therefore the RFT may reflect an underestimation of the true respiratory function). Further, no distinction was made in patients with or without pre-existing pulmonary diseases at the time of the RFT. These effects would be expected to have occurred at random across the entire data set and as such were unlikely to contribute to any systematic bias. Significant differences were found in age at injury and BMI when comparing the subset of 59 patients with the total group; however, these were small and unlikely to be clinically relevant.

Because of sample size limitations we were only able to assess the interaction between one independent variable with time since injury at a time, and therefore cannot control for confounding between variables. A larger study population would allow for controlling of more potentially explanatory variables in a multivariate mixed model analysis.

This study involved analysing a retrospective data set sourced from several databases at the Austin Hospital, and we were therefore unable to obtain reliable data on smoking history, ethnicity and change in BMI over time.

\section{CONCLUSION}

Investigation of longitudinal data of RFTs after SCI showed no overall change in (F)VC over time. Our clinical cohort data suggest that respiratory function in people with SCI does not change significantly beyond their initial drop in the lung function after injury. However, patients older than 30 years at the time of their injury and those with a BMI $>30$ are more likely to show a decline in respiratory function over time.

\section{DATA ARCHIVING}

There were no data to deposit.

\section{CONFLICT OF INTEREST}

The authors declare no conflict of interest.

\section{ACKNOWLEDGEMENTS}

This work was supported by a writing scholarship from the Institute for Breathing and Sleep.

1 Sipski ML, Richards JS. Spinal cord injury rehabilitation: state of the science. Am J Phys Med Rehabil 2006; 85: 310-342.

2 Jackson $A B$, Groomes TE. Incidence of respiratory complications following spinal cord injury. Arch Phys Med Rehabil 1994; 75: 270-275.

3 Brown R, DiMarco AF, Hoit JD, Garshick E. Respiratory dysfunction and management in spinal cord injury. Respir Care 2006; 51: 853-868.

4 Garshick E, Kelley A, Cohen SA, Garrison A, Tun CG, Gagnon D et al. A prospective assessment of mortality in chronic spinal cord injury. Spinal Cord 2005; 43: 408-416.

5 DeVivo MJ, Black KJ, Stover SL. Causes of death during the first 12 years after spinal cord injury. Arch Phys Med Rehabil 1993; 74: 248-254.

6 Strauss DJ, Devivo MJ, Paculdo DR, Shavelle RM. Trends in life expectancy after spinal cord injury. Arch Phys Med Rehabil 2006; 87: 1079-1085. 
7 Winslow C, Rozovsky J. Effect of spinal cord injury on the respiratory system. Am J Phys Med Rehabil 2003; 82: 803-814.

8 Fishburn MJ, Marino RJ, Ditunno JF Jr. Atelectasis and pneumonia in acute spinal cord injury. Arch Phys Med Rehabil 1990; 71: 197-200.

9 De Troyer A, Estenne M, Heilporn A. Mechanism of active expiration in tetraplegic subjects. N Engl J Med 1986; 314: 740-744.

10 Goldman JM, Williams SJ, Denison DM. The rib cage and abdominal components of respiratory system compliance in tetraplegic patients. Eur Respir J 1988; 1: 242-247.

11 De Troyer A, Heilporn A. Respiratory mechanics in quadriplegia. The respiratory function of the intercostal muscles. Am Rev Respir Dis 1980; 122 591-600.

12 Mueller G, de Groot S, van der Woude LH, Perret C, Michel F, Hopman MT. Prediction models and development of an easy to use open-access tool for measuring lung function of individuals with motor complete spinal cord injury. J Rehabil Med 2012; 44: 642-647.

13 Sinderby C, Weinberg J, Sullivan L, Borg J, Lindstrom L, Grassino A. Diaphragm function in patients with cervical cord injury or prior poliomyelitis infection. Spinal Cord 1996; 34: 204-213

14 Axen K, Pineda H, Shunfenthal I, Haas F. Diaphragmatic function following cervical cord injury: neurally mediated improvement. Arch Phys Med Rehabil 1985; 66: 219-222.

15 Bluechardt MH, Wiens M, Thomas SG, Plyley MJ. Repeated measurements of pulmonary function following spinal cord injury. Paraplegia 1992; 30: 768-774.

16 Haas F, Axen K, Pineda H, Gandino D, Haas A. Temporal pulmonary function changes in cervical cord injury. Arch Phys Med Rehabil 1985; 66: 139-144.

17 Loveridge B, Sanii R, Dubo HI. Breathing pattern adjustments during the first year following cervical spinal cord injury. Paraplegia 1992; 30: 479-488.

18 Lucke KT. Pulmonary management following acute SCI. J Neurosci Nurs 1998; 30 91-104.

19 Berlowitz DJ, Brown DJ, Campbell DA, Pierce RJ. A longitudinal evaluation of sleep and breathing in the first year after cervical spinal cord injury. Arch Phys Med Rehabil 2005; 86: 1193-1199.

20 Fugl-Meyer AR. Effects of respiratory muscle paralysis in tetraplegic and paraplegic patients. Scand J Rehabil Med 1971; 3: 141-150.

21 Society AT. Standardization of spirometry, 1994 update. Am J Respir Crit Care Med 1995; 152: 1107-1136.

22 Black LF, Hyatt RE. Maximal respiratory pressures: normal values and relationship to age and sex. Am Rev Respir Dis 1969; 99: 696-702.
23 Miller MR, Hankinson J, Brusasco V, Burgos F, Casaburi R, Coates A et al. Series "ATS/ ERS TASK FORCE: STANDARDISATION OF LUNG FUNCTION TESTING" standardisation of spirometry. Eur Respir J 2005; 26: 319-338.

24 DeVivo MJ, Biering-Sorensen F, New P, Chen Y. International Spinal Cord Injury Data Set Standardization of data analysis and reporting of results from the International Spinal Cord Injury Core Data Set. Spinal Cord 2011; 49: 596-599.

25 Body Mass Index database: World Health Organisation. Available at http://apps.who.int/ bmi/index.jsp? introPage = intro_3.html. Accessed on 10 March 2015.

26 Weitzenkamp DA, Jones RH, Whiteneck GG, Young DA. Ageing with spinal cord injury: cross-sectional and longitudinal effects. Spinal Cord 2001; 39: 301-309.

27 Kang SW, Shin JC, Park Cl, Moon JH, Rha DW, Cho DH. Relationship between inspiratory muscle strength and cough capacity in cervical spinal cord injured patients. Spinal Cord 2006; 44: 242-248.

28 Urmey W, Loring S, Mead J, Slutsky AS, Sarkarati M, Rossier A et al. Upper and lower rib cage deformation during breathing in quadriplegics. J App/ Physiol 1986; 60: 618-622.

29 Mueller G, de Groot S, van der Woude L, Hopman MT. Time-courses of lung function and respiratory muscle pressure generating capacity after spinal cord injury: a prospective cohort study. J Rehabil Med 2008; 40: 269-276.

30 Quanjer PH, Tammeling GJ, Cotes JE, Pedersen OF, Peslin R, Yernault JC. Lung volumes and forced ventilatory flows. Report working party standardization of lung function tests, European Community for Steel and Coal. Official statement of the European Respiratory Society. Eur Rspir J Supp/ 1993; 16: 5-40.

31 Postma K, Haisma JA, de Groot S, Hopman MT, Bergen MP. Stam HJ et al. Changes in pulmonary function during the early years after inpatient rehabilitation in persons with spinal cord injury: a prospective cohort study. Arch Phys Med Rehabil 2013; 94: 1540-1546.

32 Tow AM, Graves DE, Carter RE. Vital capacity in tetraplegics twenty years and beyond. Spinal Cord 2001; 39: 139-144.

33 Jones RL, Nzekwu MM. The effects of body mass index on lung volumes. Chest 2006; 130: 827-833.

34 Chen Y, Horne SL, Dosman JA. Body weight and weight gain related to pulmonary function decline in adults: a six year follow up study. Thorax 1993; 48: 375-380.

35 Stolzmann KL, Gagnon DR, Brown R, Tun CG, Garshick E. Longitudinal change in FEV1 and FVC in chronic spinal cord injury. Am J Respir Crit Care Med 2008; 177: 781-786.

36 van den Berg ME, Castellote JM, de Pedro-Cuesta J, Mahillo-Fernandez I. Survival after spinal cord injury: a systematic review. J Neurotrauma 2010; 27: $1517-1528$ 